\title{
Nota Científica \\ Deposição de folhedo e fluxo de nutrientes em eucalipto geneticamente modificado
}

\author{
José Luiz Ferraresso Conti Junior ${ }^{1 *}$, Paulo Henrique Muller Silva², Hilton Thadeu Zarate do Couto ${ }^{3}$ \\ ${ }^{1}$ ArborGen Tecnologia Florestal, Rua Dr. Emílio Ribas, 174, CEP 13025-140, Campinas, SP, Brasil \\ ${ }^{2}$ Instituto de Pesquisa e Estudos Florestais, Via Comendador Pedro Morganti, 3500, CEP 13415-000, Piracicaba, SP, Brasil \\ 3Universidade de São Paulo, Escola Superior de Agricultura "Luiz de Queiroz", Av. Pádua Dias, 11, CEP 13418-900, Piracicaba, SP, Brasil
}

\section{"Autor correspondente: \\ jlconti@arborgen.com}

Termos para indexação:

Ciclagem de nutrientes

Organismo transgênico

Serapilheira

Index terms:

Nutrient cycling

Transgenic organisms

Leaf litter

Histórico do artigo:

Recebido em 17/07/2015

Aprovado em 17/03/2017

Publicado em 31/03/2017

doi: 10.4336/2017.pfb.37.89.985

\begin{abstract}
Resumo - A deposição de folhedo é um dos principais indicadores de ciclagem de nutrientes em plantios florestais. O objetivo desse trabalho foi avaliar a dinâmica de deposição de folhedo, o fluxo dos nutrientes copa-solo via folhedo e a decomposição desse material em um plantio experimental de eucalipto geneticamente modificado. Não foram observadas alterações significativas na produção de folhedo ou no fluxo de nutrientes devido à transformação do eucalipto. As maiores variações observadas foram entre os dois clones estudados, mas foram inferiores às observadas comumente com as mudanças dos tratos silviculturais.
\end{abstract}

\section{Deposition of litter and nutrient flow of genetically modified eucalypts}

\begin{abstract}
The deposition of litter is a major nutrient cycling indicator in forest plantations. The objective of this study was to evaluate dynamics of leaf litter deposition, flow of nutrients from canopy to soil via litter and decomposition of this material in a genetically modified eucalyptus plantation. There were no significant changes in leaf litter production or in nutrients flow due to eucalypts genetic modification. Largest variation was observed between the two studied clones, but they were lower than that commonly observed with changes of silvicultural treatments.
\end{abstract}

No Brasil, o melhoramento genético do eucalipto intensificou-se na década de 1960, muitos anos após os trabalhos de seleção de espécies realizados no Horto Florestal de Rio Claro, SP. Eucalyptus grandis foi a espécie selecionada com a qual se iniciou o plantio extensivo e o melhoramento interespecífico, com a seleção de progênies e a introdução de origens mais adequadas para o país. Na década de 1980 foi a vez dos clones híbridos de E. urophylla x E. grandis serem trabalhados intensivamente, gerando ganhos de produtividade devido à tolerância ao cancro, capacidade de rebrota, uniformidade entre as árvores, entre outras qualidades. Estes ganhos foram potencializados com o avanço de técnicas silviculturais, como preparo de solo, controle de mato, manejo integrado de pragas/doenças e adequada fertilização (Gonçalves et al., 2013; Silva et al., 2013).

Atualmente, existe a possibilidade da transformação genética para a obtenção de novos genótipos mais produtivos e/ou mais tolerantes aos estresses bióticos ou abióticos (Xu et al., 1996; Huang et al., 2012; Dubouzet et al., 2013). Alguns autores estudaram o efeito do 
uso comercial de culturas florestais geneticamente modificadas no ambiente (Andreote et al., 2009). Entretanto, mais estudos são necessários para verificar os reais ganhos da utilização de árvores transformadas e os impactos do plantio de organismos geneticamente modificados (OGM) no ambiente (Snow \& MoránPalma, 1997; Frankenhuyzen \& Beardmore, 2004), especialmente para a cultura do eucalipto, a qual se tem muito interesse científico e comercial.

Dentre várias características mensuráveis, a ciclagem de nutrientes em plantios de eucalipto permite avaliar possíveis alterações relacionadas às técnicas de manejo e possibilita discutir a sustentabilidade florestal. Por isso, esse trabalho tem por objetivo avaliar a dinâmica de deposição de folhedo, o fluxo de nutrientes da copa para o solo e a taxa de decomposição desse material em um talhão experimental com plantios de eucalipto transgênico e convencional.

$\mathrm{O}$ experimento com eucalipto transformado foi instalado no Município de Paranapanema, SP, em uma área de antiga pastagem. A região apresenta clima subtropical Cfa (clima temperado úmido com verão quente) segundo a classificação climática de Köppen. O solo foi classificado como Latossolo Vermelho-Amarelo Distrófico típico (Sistema..., 1999), textura médioargilosa e relevo plano.

O clone base da transformação foi um híbrido de E. urophylla $x$ E. grandis, sendo implantadas 62 linhagens/eventos. O material foi modificado com DNA exógeno transferido através da bactéria Agrobacterium tumefaciens, com o objetivo alterar a composição química na planta, buscando diminuir o teor de lignina e aumentar o rendimento no processo da celulose. Além dos eventos geneticamente modificados (GM) foram avaliados dois clones sem transformação: o clone base para transformação não geneticamente modificado (N-GM/clone 1) e outro clone distinto não geneticamente modificado híbrido de E. urophylla $x$ E. grandis (clone 2).

A transformação foi realizada nos EUA e em 2008 as plantas foram importadas para experimentação, sendo realizada a implantação do experimento em outubro de 2009. O período entre a importação e implantação se deve ao trabalho de produção das mudas em número e qualidade adequadas. $\mathrm{O}$ espaçamento de plantio foi de $2,7 \mathrm{~m} \times 2,7 \mathrm{~m}$, sendo o delineamento de uma planta por parcela com 20 repetições distribuídas aleatoriamente em blocos casualizados no experimento.
Para análise de deposição de serapilheira foram instalados 40 coletores de $0,5 \mathrm{~m}$ x $0,5 \mathrm{~m}$ nas parcelas com clone GM e 40 coletores nos clones não transformados, sendo 20 para cada um deles (clone 1 e clone 2). Os coletores foram distribuídos nas linhas e entre-linhas de plantio. As coletas foram realizadas a cada dois meses entre o período de janeiro de 2013 a março de 2014, quando o experimento estava com quatro anos. Após a coleta, as amostras foram secas em estufa $\left(65^{\circ} \mathrm{C}\right.$ por $72 \mathrm{~h}$ ), para posterior pesagem e realização das análises dos macronutrientes ( $\mathrm{N}, \mathrm{P}$ e K).

No mesmo período, para o estudo da decomposição de folhedo, foram instaladas 100 bolsas de polivinil (litterbags), sendo 50 com folhedo oriundo de plantas GM, 25 com folhedo do clone 1 e 25 com folhedo do clone 2, com peso úmido padrão de $10 \mathrm{~g}$ por bolsa decompositora. As bolsas de decomposição foram colocadas na superfície do solo dentro do experimento. Foram realizadas quatro coletas: 45, 90, 180 e 360 dias para avaliação da taxa de decomposição. O material foi pesado após a secagem em estufa a $60{ }^{\circ} \mathrm{C}$ por $72 \mathrm{~h}$.

Para comparação das médias, foi realizada a análise de variância (ANOVA) e o teste complementar de Tukey (Steel et al., 1997). Para cada variável estudada foi realizado o teste de normalidade (Shapiro-Wilk) e de homogeneidade de variâncias (Box-Cox).

A produção de folhedo durante a condução do experimento não apresentou diferença significativa entre os tratamentos. Em média, a produção de folhedo pelos clones de eucalipto foi de $2,5 \mathrm{t} \mathrm{ha}^{-1}$ ano $^{-1}$, que é inferior aos valores encontrados na literatura para a produção de folhedo por eucaliptos no Brasil (Silva et al., 2011; Schumacher et al., 2013; Vieira et al., 2014). Essa diferença na produção de folhedo deve-se a fatores como idade do plantio, intensidade de competição entre as plantas, condições ambientais e material genético avaliado.

A maior produção de folhedo teve início em agosto, período de menor pluviosidade (Figura 1). Segundo Silva et al. (2011) existe interação entre o período de estresse hídrico (seca) e a produção de folhedo, sendo obtidas as maiores taxas de produção no início da estiagem. $\mathrm{O}$ estresse causado pela seca eleva a síntese de etileno, cuja resposta consiste na abscisão foliar, que é uma das primeiras mudanças na planta para tolerar a seca (Taiz \& Zeiger, 2010). 


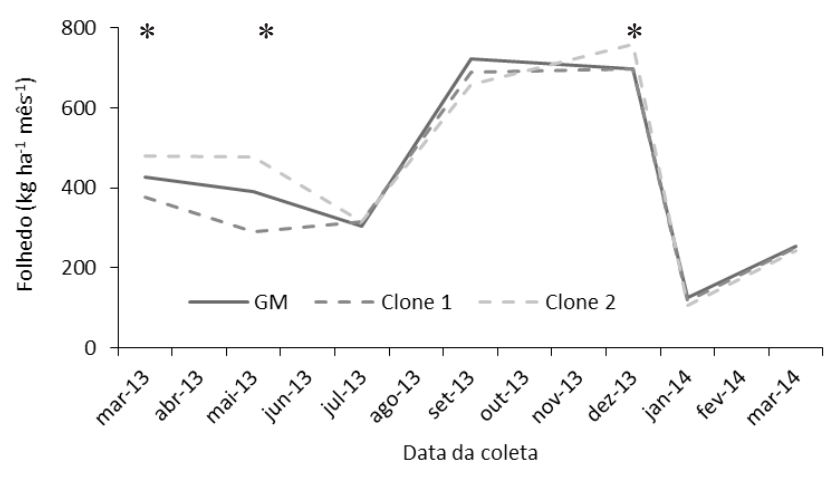

Figura 1. Produção mensal de biomassa de folhedo durante um ano. $\mathrm{GM}=$ geneticamente modificado; * diferença significativa entre os tratamentos.
Foram observadas diferenças significativas entre os tratamentos na concentração de potássio depositado no solo via folhedo, não sendo observada diferença para os outros nutrientes avaliados $(\mathrm{N}$ e $\mathrm{P})$, como pode ser observado na Tabela 1. As maiores variações encontradas foram entre os períodos de coleta, mas sem interação com os tratamentos. As concentrações dos nutrientes estão similares a outros estudos realizados com eucalipto. No entanto, o fluxo de nutrientes está um pouco abaixo, devido a menor biomassa de folhedo produzido (Silva et al., 2011, 2013).

Neste estudo, em um ano, o fluxo de nitrogênio da copa para o solo via folhedo foi superior a $32 \mathrm{~kg} \mathrm{ha}^{-1}$ enquanto fosforo e potássio resultaram em $3 \mathrm{~kg} \mathrm{ha}^{-1} \mathrm{e}$ $11 \mathrm{~kg} \mathrm{ha}^{-1}$, respectivamente (Tabela 1). A quantidade aportada de $\mathrm{N}$ em um ano neste estudo correspondeu de 30 a $50 \%$ da recomendação atual do nutriente para todo o ciclo do eucalipto (Gonçalves et al., 2013).

Tabela 1. Concentração de folhedo e fluxo de nutrientes da copa para o solo em 2013/2014.

\begin{tabular}{|c|c|c|c|c|c|c|c|c|c|c|c|c|c|c|c|}
\hline \multicolumn{16}{|c|}{ Concentração dos nutrientes $\left(\mathrm{g} \mathrm{kg}^{-1}\right)$} \\
\hline \multirow[t]{2}{*}{ Nutriente } & \multirow{2}{*}{$\begin{array}{l}\text { Trat } \\
\text { GM }\end{array}$} & \multicolumn{2}{|c|}{ Mar/13 } & \multicolumn{2}{|c|}{ Mai/13 } & \multicolumn{2}{|c|}{$\mathbf{J u l} / \mathbf{1 3}$} & \multicolumn{2}{|c|}{ Set/13 } & \multicolumn{2}{|c|}{ Dez/13 } & \multicolumn{2}{|c|}{ Jan/14 } & \multicolumn{2}{|c|}{ Média } \\
\hline & & 8,04 & $\mathrm{a}$ & 6,35 & $\mathrm{a}$ & 6,87 & $\mathrm{a}$ & 7,22 & a & 6,65 & $\mathrm{~b}$ & 15,11 & a & 8,37 & a \\
\hline \multirow[t]{3}{*}{$\mathrm{N}$} & Clone 2 & 6,85 & $\mathrm{a}$ & 5,24 & $\mathrm{~b}$ & 6,14 & $\mathrm{a}$ & 6,46 & a & 7,16 & $\mathrm{a}$ & 11,28 & $\mathrm{~b}$ & 7,19 & a \\
\hline & Clone 1 & 7,57 & a & 5,49 & $\mathrm{ab}$ & 6,46 & a & 6,43 & a & 7,07 & $\mathrm{ab}$ & 9,47 & $\mathrm{~b}$ & 7,08 & a \\
\hline & GM & 0,55 & $a b$ & 0,88 & $\mathrm{~b}$ & 0,59 & $a b$ & 0,59 & $\mathrm{a}$ & 0,41 & $\mathrm{a}$ & 0,41 & $\mathrm{a}$ & 0,57 & $a b$ \\
\hline \multirow[t]{3}{*}{$\mathrm{P}$} & Clone 2 & 0,62 & $\mathrm{a}$ & 1,61 & a & 0,76 & a & 0,64 & a & 0,47 & $\mathrm{a}$ & 0,45 & a & 0,76 & a \\
\hline & Clone 1 & 0,45 & $\mathrm{~b}$ & 0,64 & $\mathrm{c}$ & 0,47 & $\mathrm{~b}$ & 0,45 & $\mathrm{a}$ & 0,38 & $\mathrm{a}$ & 0,46 & $\mathrm{a}$ & 0,48 & $\mathrm{~b}$ \\
\hline & GM & 1,16 & $\mathrm{~b}$ & 2,45 & $\mathrm{~b}$ & 1,43 & $\mathrm{a}$ & 1,43 & b & 2,23 & $a b$ & 2,30 & a & 1,83 & $\mathrm{~b}$ \\
\hline \multirow[t]{2}{*}{ K } & Clone 2 & 1,76 & $\mathrm{a}$ & 5,16 & $\mathrm{a}$ & 1,57 & $\mathrm{a}$ & 2,33 & $\mathrm{a}$ & 2,75 & $\mathrm{a}$ & 2,04 & $\mathrm{a}$ & 2,60 & $\mathrm{a}$ \\
\hline & Clone 1 & 1,23 & $a b$ & 3,06 & $a b$ & 1,15 & $\mathrm{~b}$ & 1,09 & $\mathrm{c}$ & 1,79 & $\mathrm{~b}$ & 1,98 & a & 1,72 & $\mathrm{~b}$ \\
\hline \multicolumn{16}{|c|}{ Fluxo de nutrientes $\left(\mathrm{kg} \mathrm{ha}^{-1}\right)$} \\
\hline Nutriente & Trat & \multicolumn{2}{|c|}{ Mar/13 } & \multicolumn{2}{|c|}{ Mai/13 } & \multicolumn{2}{|c|}{$\mathrm{Jul} / \mathbf{1 3}$} & \multicolumn{2}{|c|}{ Set/13 } & \multicolumn{2}{|c|}{ Dez/13 } & \multicolumn{2}{|c|}{ Jan/14 } & \multicolumn{2}{|c|}{ Total } \\
\hline \multirow{3}{*}{$\mathrm{N}$} & GM & 6,89 & $\mathrm{ab}$ & 4,97 & $\mathrm{ab}$ & 4,19 & a & 10,44 & a & 9,28 & a & 1,68 & a & 37,44 & a \\
\hline & Clone 2 & 5,17 & $\mathrm{~b}$ & 3,05 & $\mathrm{~b}$ & 3,89 & $\mathrm{a}$ & 8,91 & a & 10 & $\mathrm{a}$ & 1,70 & $\mathrm{a}$ & 32,72 & $\mathrm{a}$ \\
\hline & Clone 1 & 7,27 & a & 5,24 & a & 4,08 & a & 8,47 & a & 10,74 & a & 1,50 & a & 37,29 & a \\
\hline \multirow{3}{*}{$P$} & GM & 0,47 & $\mathrm{a}$ & 0,69 & $\mathrm{ab}$ & 0,36 & $\mathrm{a}$ & 0,85 & a & 0,57 & $\mathrm{a}$ & 0,10 & $\mathrm{a}$ & 3,05 & $a b$ \\
\hline & Clone 2 & 0,46 & $a b$ & 0,94 & $\mathrm{a}$ & 0,48 & $\mathrm{a}$ & 0,88 & a & 0,66 & $\mathrm{a}$ & 0,11 & a & 3,53 & a \\
\hline & Clone 1 & 0,43 & $\mathrm{~b}$ & 0,61 & $\mathrm{~b}$ & 0,30 & $\mathrm{a}$ & 0,59 & $\mathrm{~b}$ & 0,58 & $\mathrm{a}$ & 0,10 & $\mathrm{a}$ & 2,61 & $\mathrm{~b}$ \\
\hline \multirow{3}{*}{ K } & GM & 0,99 & $\mathrm{~b}$ & 1,92 & $\mathrm{~b}$ & 0,87 & $\mathrm{a}$ & 2,07 & b & 3,11 & $\mathrm{a}$ & 0,58 & a & 9,54 & $\mathrm{~b}$ \\
\hline & Clone 2 & 1,33 & $\mathrm{a}$ & 3,01 & $\mathrm{a}$ & 0,99 & $\mathrm{a}$ & 3,21 & $\mathrm{a}$ & 3,84 & $\mathrm{a}$ & 0,48 & $\mathrm{a}$ & 12,87 & $\mathrm{a}$ \\
\hline & Clone 1 & 1,18 & $a b$ & 2,92 & $a b$ & 0,73 & $\mathrm{a}$ & 1,44 & $\mathrm{~b}$ & 2,72 & $\mathrm{a}$ & 0,42 & a & 9,40 & $\mathrm{~b}$ \\
\hline
\end{tabular}


Não foi observada diferença na taxa de decomposição de folhedo entre os tratamentos (gráfico não apresentado). Foi obtida uma regressão exponencial média ( $\mathrm{y}=$ $\left.3.7062 \mathrm{e}^{-0.002 x}\right)$ altamente significativa $\left(\mathrm{R}^{2}=0,9848\right)$, ou seja, a decomposição tem forte relação com o tempo, independente do tratamento (material GM e N-GM).

A ciclagem dos nutrientes no ecossistema está relacionada à sustentabilidade do plantio florestal, sendo que a devolução de nutrientes via serapilheira depositada é a principal fonte de carbono e nutrientes para o solo (Bray \& Ghoram, 1964). Ressalta-se que alterações nos teores de lignina ou da relação entre os elementos na serapilheira podem causar mudanças na degradação do material em condições de campo, alterando a ciclagem dos nutrientes. Neste trabalho, as maiores variações observadas foram entre os dois clones. No entanto, mesmo essas variações observadas não foram biologicamente significativas e foram inferiores às observadas comumente com as mudanças dos tratos silviculturais, principalmente de fertilização aplicada ao plantio de eucalipto (Laclau et al., 2003; Silva et al., 2013).

\section{Conclusão}

A deposição de folhedo, o fluxo de nutrientes da copa ao solo e a decomposição de folhedo não apresentaram diferenças significativas devido à transformação genética estudada.

\section{Referências}

Andreote, F. D. et al. Bacterial community in the rhizosphere and rhizoplane of wild type and transgenic eucalyptus. World Journal of Microbiol Biotechnol, v. 25, n. 6, p. 1065-1073, 2009. DOI: 10.1007/s11274-009-9990-9.

Bray, J. R. \& Ghoram, E. Litter production in forests of the world. In: Cragg, J. B. (Ed.). Advances in ecological research. London: Academic Press, 1964. v. 2. p. 101-154.

Dubouzet, J. G. et al. Potential transgenic routes to increase tree biomass. Plant Science, v. 212, p. 72-101, 2013. DOI: 10.1016/j. plantsci.2013.08.006.
Frankenhuyzen, K. U. \& Beardmore, T. Current status and environmental impact of transgenic forest trees. Canadian Journal of Forest Research, v. 34, n. 6, p. 1163-1180, 2004. DOI: 10.1139/ x04-024.

Gonçalves, J. L. M. et al. Integrating genetic and silvicultural strategies to minimize abiotic and biotic constraints in Brazilian eucalypt plantations. Forest Ecology and Management, v. 301, p. 6-27, 2013. DOI: 10.1016/j.foreco.2012.12.030.

Huang, Y. et al. Combined expression of antimicrobial genes (Bbchit1 and LJAMP2) in transgenic poplar enhances resistance to fungal pathogens. Tree Physiology, v. 32, n. 10, p. 1313-1320, 2012. DOI: 10.1093/treephys/tps079.

Laclau, J.-P. et al. Nutrient dynamics throughout the rotation of Eucalyptus clonal stands in Congo. Annals of Botany, v. 91, 879-892, 2003. DOI: 10.1093/aob/mcg093.

Schumacher, M. V. et al. Produção e decomposição de serapilheira em um povoamento de Eucalyptus urophylla $x$ Eucalyptus globulus maidenii. Cerne, v. 19, n. 3, 501-508, 2013. DOI: 10.1590/S010477602013000300018 .

Silva, P. H. M. et al. Applying sewage sludge to Eucalyptus grandis plantations: effects on biomass production and nutrient cycling through litterfall. Applied Environmental Soil Science, v. 2011, article ID 7161, 11 p. DOI: 10.1155/2011/710614.

Silva, P. H. M. et al. Fertilizer management of eucalypt plantations on sandy soil in Brazil: initial growth and nutrient cycling. Forest Ecology and Management, v. 301, p. 67-78 , 2013. DOI: 10.1016/j. foreco.2012.10.033.

Sistema Brasileiro de classificação de solos. Brasília, DF: Embrapa Produção de Informação; Rio de Janeiro: Embrapa Solos, 1999. $412 \mathrm{p}$.

Snow, A. A. \& Morán-Palma, P. Commercialization of transgenic plants: potential ecological risks. Bioscience, v. 47, n. 2, p. 86-96, 1997. DOI: $10.2307 / 1313019$.

Steel, R. G. D. et al. Principles and procedures of statistics: a biometrical approach. 3rd ed. Boston: McGraw Hill, 1997. 666 p.

Taiz, L. \& Zeiger, E. Fisiologia vegetal. 4. ed. Porto Alegre: Artmed, 2010. 819 p.

Viera, M. et al. Deposição de serapilheira e nutrientes em plantio de Eucalyptus urophylla $\times$ E. globulus. Floresta e Ambiente, v. 21, n. 3, p. 327-338, 2014. DOI: 10.1590/2179-8087.053913.

$\mathrm{Xu}, \mathrm{D}$. et al. Expression of a late embryogenesis abundant protein gene, HVA1, from barley confers tolerance to water deficit and salt stress in transgenic rice. Plant Physiology, v. 110, n. 1, p. 249-257, 1996. 